\title{
NACIONALISMO COMO TRADIÇÃO NA LITERATURA PORTUGUESA
}

\section{NATIONALISM AS TRADITION IN PORTUGUESE LITERATURE}

Danglei Castro Pereira'

RESUMO: $O$ artigo comenta o nacionalismo enquanto tema na literatura portuguesa, tomando como premissa inicial a ideia de que os temas literários, dentro de uma tradiçăo, manifestam pontos de confluência. Abordaremos o sentido de resgate cultural e a valorizaçáo do histórico como recorrente na literatura em Portugal. Nosso principal objetivo é comentar como a presença do nacionalismo apresenta-se como tensâo temática na literatura portuguesa por meio do cotejo de diferentes obras. O estudo focaliza, entăo, a permanência e distanciamento do nacionalismo no construto da tradiçăo literária em Portugal.

Palavras chave: literatura portuguesa, tradiçấo, nacionalismo.

ABSTRACT: The article comments nationalism as an issue in Portuguese literature, taking as a starting premise the idea that literary themes, within a tradition, manifest points of confluence. We discuss the meaning of cultural revival and development of the historical as recurring in the literature in Portugal. Our main goal is to comment the presence of nationalism as a thematic tension in Portuguese literature through the collation of various works. The study focuses on the permanence and detachment of nationalism in the construct of the literary tradition in Portugal.

Keywords: Portuguese literature, tradition, nationalism.

\section{INTRODUÇÃO}

Ao abordarmos a presença do nacionalismo como tema revisitado na literatura portuguesa, acreditamos ser pertinente discutir, inicialmente, a delimitaçăo do conceito de tradiçấo, entendido aqui, na aresta do que propóe Todorov (1994). Para Todorov (1994) a tradiçấo resulta do contato e ressonâncias temáticas e/ou estéticas em diferentes obras ao longo do tempo, o que delimita uma fonte temática de influência dentro de um conjunto de produçōes literárias em dada sociedade. É por meio da tradiçâo que os temas culturais sâo retomados e discutidos ao longo do tempo, conduzindo, neste percurso, a pontos temáticos em constante diálogo dentro de uma tradiçâo.

Bloom (1994) comenta que um texto sempre remonta a uma obra anterior, atualizando, ampliando ou revitalizando temas ao longo do tempo. Estes temas estabelecem

Universidade de Brasília / danglei@unb.br 
diálogos nem sempre amigáveis com o presente, formando elos de influência ligados aos valores culturais de determinada sociedade. É, no entanto, pelas proximidades estilísticas e pelas recorrências temáticas ora tensivas ora confluentes que pensamos em uma linha temática recorrente em dada diversidade paradigmática no constructo historiográfico em literatura.

Chamamos a atençâo para o fato de que é no interior dos diálogos entre textos, perceptíveis ao longo do tempo histórico, que as fontes ou paradigmas estéticos/temáticos de uma tradiçâo sâo revitalizados em um processo contínuo de construçâo e recuperaçấo dos textos literários como fontes da tradiçăo ao longo do tempo, o que incluiria os diálogos intertextuais, conforme Bakhtin (1994)².

Para Anatol Rosenfeld (1976) essa constante revitalizaçăo de temas e estilos constrói-se a partir do que o crítico delimita como o Zeitgeist, ou seja, o espírito unificador que interliga todas as manifestaçôes literárias em um determinado recorte temporal dentro da tradiçấo. O Zeitgeist, neste sentido, é parte integrante na construçấo da tradiçăo, pois remonta em nível profundo a manutençăo de temas e posicionamentos ideológicos cifrados nas estruturas textualizadas.

No escopo deste trabalho discutimos a permanência do nacionalismo como tema na tradiçáo literária portuguesa pensando em um percurso histórico dentro do que podemos classificar como continum de tradiçăo. A idéia de continum, recuperada das consideraçôes de Bloom (1994), é compreendida como diálogo entre diferentes fontes literárias ao longo do tempo. Neste, as constantes interferências e atualizaçôes de um tema, quando de sua evocaçáo em obras literárias, produz uma proximidade temática perceptível em diferentes contextos de produçấo.

O percurso adotado, neste sentido, comenta a organizaçấo do nacionalismo e a busca por afirmaçăo da cultura portuguesa e, por fim, a permanência deste tema em autores como Carlos Oliveira e Antonio Lobo Antunes. Entendemos que o resultado desta permanência pode ser compreendido em um espaço derrisivo face à utopia nacionalista na tradiçăo literária portuguesa.

O trabalho propóe como hipótese a presença de um percurso ufanista e sua reorganizaçăo reflexiva ao longo do tempo na literatura em Portugal.

\section{DUAS FACES DO NACIONALISMO NA LITERATURA PORTUGUESA}

Feitos os comentários iniciais, passamos a um aspecto temático relevante para o desenvolvimento do trabalho: delimitar a ideia de nacionalismo que iremos adotar neste texto. Machado de Assis (1987), em "Instinto de nacionalidade", comenta que o nacionalismo é um percurso temático que filtra diferenças culturais rumo à afirmaçăo do singular e do individual, sem, contudo, fixar exageradamente a visấo de cunho nacionalista exclusivamente sob o escopo do exótico e pitoresco, comuns às representaçōes indianistas do romantismo brasileiro, por exemplo.

2 Năo cabe aqui discutir pormenorizadamente o conceito de intertextualidade, dialogismo ou polifonia, como proposto por Bakhtin (1994), antes indicar que a recuperaçăo estilística de diferentes textos ao longo do tempo implica, também, em adequaçōes temáticas dispersas no tempo histórico. Esta temática amplia por demais as discussōes deste artigo e, por isso, será retomada em estudos futuros. 
Para o crítico, o nacionalismo suplanta os localismos em um processo de reconduçâo da ideia de identidade filiada ao exótico e pitoresco como única forma de expressăo do viés nacionalista. Esta visăo do nacionalismo dialoga tensivamente com as consideraçôes de Almeida Garrett (1978, p. 305), por contingência, Ferdinand Denis (1978) e, no Brasil, Gonçalves de Magalhāes (1978) para quem o nacionalismo passa pela afirmaçăo da diferença, portando, do singular e do local, muitas vezes, amalgamado à ideia de exótico e pitoresco.

Em Garrett (1978) a exaltaçâo da terra e dos costumes do homem português em Viagens na minha terra questiona a artificialidade das ninfas neoclássicas deslocadas para o vale do Tejo em uma visăo derrisória da tradiçăo árcade, que parece, aos olhos do narrador das viagens, descaracterizar a afirmaçăo do nacional. O resultado é um nacionalismo que aponta para a afirmaçăo do local como singular e, por isso, se volta para a focalizaçấo do espaço lusitano como fonte de identificaçáo à cultura portuguesa em uma clara contestaçăo às influências francesas e inglesas na cultura lusitana na segunda metade do século XIX.

Garrett (1978) propóe, entâo, a veiculaçăo do nacional à necessidade de os poetas elegerem elementos representativos do espaço natural ao qual estâo ligados. Para o poeta:

a imensa cópia das composiçóes pastoris, as quais năo săo riqueza, mas desperdício de nossas musas, ou pecam por empoladas, por inverossímeis, por baixas, por demasiado naturais, por sobejo elevadas. Um meio termo dificílimo de tocar, de nele permanecer, um estilo singelo como o campo, mas năo rústico como as brenhas, sáo dos mais difíceis requisitos que de um poeta pode exigir. (GARRETT, 1978, p. 305)

Quando retomamos Garrett (1978) e Assis (1987) o fazemos como forma de identificar um ponto tensivo face à temática nacionalista e que parece importante para pensarmos a tradiçáo nacionalista na literatura portuguesa. Assis (1987) opera uma crítica ao tom exótico e pitoresco como necessário para a construçăo de um nacionalismo mais amplo que, segundo o autor, caminha em direçăo ao tom universal; ao passo que Garrett aponta a necessidade de afirmaçăo da cor local como um caminho para o nacionalismo. Em outros termos, Garrett (1978), no excerto supracitado, fala em "brenhas" em "desperdício de nossas musas" como forma de apontar para a necessidade de valorizaçăo do contexto português face às correntes que influenciavam as produçóes literárias portuguesas no século XIX; ao passo que Assis (1987) compreende como nacional a adoçâo de procedimentos mais abstratos que filtram as influências como forma de expressấo do local sem, contudo, fixar-se exageradamente no pitoresco e no exótico do cenário nacional, no caso, falando da tradiçăo brasileira.

A construçăo de um processo de síntese entre o exagero "brenhas" e o "singelo campo" é apontado por Garrett (1978) como um caminho intermediário na focalizaçâo do espaço como forma de delimitar o tom natural que, em nível profundo, remete a ideia de nacionalidade, de pertencimento. A confluência entre a visăo mais abstrata de Assis (1987) e a busca pela identificaçăo ao local em Garrett (1978) é possível quando pensamos que os dois autores parecem compreender a importância de traços de nacionalidade literária; mas indicam caminhos tensivos presentes na focalizaçâo do espaço natural na literatura de fundo nacionalista. Pensamos, neste sentido, que 
nos dois autores as diferenças estéticas - adoçăo ou năo de traços identitários ligados aos elementos representativos da "cor local" - filtram influências mais profundas, passando, neste percurso, por uma acomodaçáo dos temas locais em direçáo ao nacionalismo em um caráter mais abstrato e, por vezes, questionador face ao exótico e o pitoresco.

É justamente o sentido de permanência ao local e sua reorganizaçăo para além do exótico e do pitoresco que possibilita a aproximaçăo das consideraçōes de Assis (1987) e Garrett (1978). Entendemos que os dois autores, embora apresentem pontos de divergência quanto à alusâo aos elementos naturais de cada regiâo, Brasil e Portugal, empreendem uma contraposiçấo aos "localismos universais". A necessidade de focar a realidade específica como forma de marcar uma identidade aparece nos dois autores como decorrente de uma visáo mais abstrata face ao exótico e o pitoresco, o que desloca o olhar nacionalista de uma visada puramente ufanista ligada a este espaço.

A valorizaçăo do espaço e do homem lusitano na obra de Garrett encontra no poema "Camóes" e em Viagens na minha terra, exemplos contundentes. No poema "Camóes" o eu-lírico embebido por um sentido de nacionalidade valoriza a tradiçâo literária como forma de exaltar a naçăo portuguesa. Camôes evocado como personagem de um poema, em muito ufanista, representa o retorno à tradiçáo e expóe a fratura política e econômica pela qual passa Portugal sob a ameaça de invasâo napoleônica e inglesa.

Este percurso de valorizaçăo do local como prolongamento do histórico em direçăo a uma crítica a descaracterizaçáo do local pode ser observado no contato tensivo do lusitano com o outro em Eurico, o presbítero, de Alexandre Herculano. Neste romance histórico a figura de Eurico transfigurado no Cavaleiro negro encarna o valor do homem lusitano e, ao mesmo tempo, expóe sua fratura, posto que os valores dogmáticos, implícitos na construçāo do personagem, apontam ironicamente para a decadência do modelo medieval português. Isto conduz a uma ironia subjacente na construçâo do personagem face à estagnaçăo do homem lusitano preso aos valores remissivos do passado, lembremos o recuo histórico do romance em discussâo, mas em franca modernizaçâo na Europa do século XIX, momento em que o romance é escrito.

Teríamos em Garrett e Herculano, vozes de afirmaçăo do nacionalismo na correlaçăo espaço nacional e fatores históricos ligados a um passado lusitano, porém ultrapassado no limiar do século XX na Europa e, sobretudo, em Portugal ao final do século XIX. Este percurso de resgate ufanista do passado, porém, deixa implícita a fragilidade de compreender o nacionalismo português na relaçăo harmônica entre estado de alma lusitana de fundo medieval e as transformaçóes do espaço natural face aos valores históricos de fim de século XIX em Portugal.

O resultado é a construçăo de personagens fragmentados que buscam o contato com a tradiçấo medieval, mas ao fazê-lo expóe a contaminaçấo do sentido de pureza ou integridade do português em contato com o outro em um processo histórico de espoliaçăo econômica e dependência política, sobretudo após as guerras napoleônicas. É neste prolongamento que as fraturas internas da cultura lusitana podem ser entendidas como temas em convivência tensiva com o passado de glórias da naçăo lusitana e sua iminente decadência ao final do século XVIII com desdobramentos até a primeira metade do século XX. 


\section{OS LUSÍADAS: UMA FONTE}

Antes de iniciarmos esta etapa da discussăo, lembramos, novamente, que compreendemos o termo tradiçâo como resultado de recorrências temáticas e estéticas dispersas ao longo das obras literárias. É por meio destas retomadas que encaminhamos a discussấo dos textos citados até este momento do trabalho como representantes do nacionalismo português, para além da afirmaçáo do local como proposto por Garrett.

A ideia de nacionalismo ganha força na tradiçăo portuguesa nos primórdios da constituiçâo de Portugal como país de grande influência no contexto europeu até o final do século XVI por meio da expansáo ultramarina. O poema épico Os Lusíadas pode ser lembrado como uma das importantes fontes para a compreensâo do nacionalismo português neste contexto histórico. No dizer de Saraiva (1990) o nacionalismo português é resultado de uma tentativa de manutençăo do valor e grandiosidade de Portugal face às dificuldades históricas enfrentadas pelo país ao longo dos séculos e os Lusíadas encarnam o espírito grandioso do homem lusitano e, por vezes, do homem ibérico.

O nacionalismo em Os Lusíadas é movido, neste sentido, por um sentimento de busca e valorizaçâo das raízes de Portugal, sua gente e cultura. Os Lusíadas, no dizer de Victor Ramos (1974), representa o

contraste dramático entre um sonho que se queria grande e uma realidade que se mostrou pior do que tudo quanto se previa, esse choque brutal que, de um dia para outro, deu outro sentido à epopeia. Após 1580 falar da missăo imperial lusíada poderia parecer uma dolorosa ironia, referir as glórias passadas era um acerbo remexer de ferida. (RAMOS, 1974, p.14)

"O contraste dramático" nas palavras de Ramos (1974) ilustra a idéia de uma ironia permeando a composiçāo das glórias das "armas e os barôes assinalados/Que, da ocidental praia lusitana,/Por mares nunca dantes navegados,/ Passam ainda além da Tropabana". Por um lado, teríamos no poema épico camoniano a expressâo das glorias do povo português metaforizadas na figura heróica de Vasco da Gama e na narraçăo entusiasmada dos feitos e vitórias dos reis lusitanos; por outro, a inferência da queda do imperialismo marítimo e a posterior decadência econômica de Portugal após o século XVIII.

O fracasso ou fragilidade da grandiosidade do homem luso cria um movimento interno de ironia dentro do poema épico, posto que o valor do herói individual em Vasco da Gama perde espaço quanto associado ao tom de advertência perceptível em algumas passagens do poema. Esta ideia pode lançar luz ao tom inquiridor presente, por exemplo, no episódio do "Velho do Restelho", só para citarmos um momento em que fica explicito o tom de preocupaçăo imposto pelo eu-épico diante dos feitos dos portugueses.

A deterioraçâo dos valores lusitanos em decorrência das riquezas encontradas no Novo mundo aponta, em nível profundo, para a desorganizaçáo econômica e social imposta pelas viagens ultramarinas no contexto histórico de Portugal. Pensamos que o viés épico de tom ufanista em Os lusíadas incorpora uma visâo irônica, concordando com Ramos (1974), uma vez que à grandeza dos feitos de Vasco da Gama - metáfora individual do povo lusitano - subjaz à consciência da fragilidade do imperialismo lusitano e dos ganhos culturais adquiridos na aventura ultramarina de Portugal em terras desconhecidas. 
Ao identificarmos este paradoxo por um lado, Os Lusíadas expressa a necessidade de valorizaçấo do espaço e da cultura de Portugal como apontado nas alusóes a Almeida Garrett e Alexandre Herculano; mas, por outro, cria um efeito de advertência que alude à fragilidade do imperialismo lusitano em fragmentos como, por exemplo, o Velho do Restelho, a fala das lavadeiras, a visăo messiânica de fundo sebastianista e a composiçâo do episódio lírico-amoroso de fundo trágico de Inês de Castro.

Surge, neste sentido, uma linha temática que afirma a fragmentaçâo cultural de Portugal ao apontar para a fragilidade do sentido de permanência do homem lusitano como detentor das glórias imortalizadas na proposiçâo de Os Lusíadas. Nesta linha de leitura, em Os Lusíadas teríamos um paralelo entre a grandiosidade das vitórias de Vasco da Gama em episódios como a "ilha dos amores", nas descriçóes entusiasmadas da perícia bélica portuguesa e nos inúmeros comentários de fundo histórico que perpassam a obra, contraposto ao viés irônico implícito, por exemplo, na visâo do eu-épico que acredita nesses feitos, mas, para isso, ignora os apelos de permanência, de retorno às origens diluído ao longo do poema, sobretudo, nos episódios comentados no parágrafo anterior.

O nacionalismo em Os Lusíadas, nesta linha de raciocínio, é formado por um viés dialético que conjuga euforia e consciência crítica, para năo dizer, ironia. Pensando nisso, podemos identificar dois paradigmas formativos do percurso nacionalista em Portugal: a valorizaçăo nostálgica da grandiosidade lusitana e a percepçâo crítica da fragilidade desta valorizaçăo. Ambos estariam subjacentes à composiçấo de $O s$ Lusíadas que, por isso, é tomado neste trabalho como fonte para as discussôes que seguem.

\section{O DUPLO COMO PONTO DE PARTIDA NA TRADIÇÃO PORTUGUESA}

Em A ilustre casa dos Ramires e A cidade e a serras, de Eça de Queiroz teríamos exemplos de como a dualidade apontada há pouco é sentida ao longo da tradiçăo literária em Portugal, o que problematiza a compreensăo do nacionalismo ufanista como único caminho construtivo deste viés temático na tradiçấo portuguesa. No caso de Eça de Queiroz a presença do saudosismo e da melancolia diante de um Portugal em estado de transformaçáo econômica em meados do século XIX dita o tom saudosista de Gonçalo Ramires na composiçăo da novela histórica "A torre de D. Ramires", espécie de nobiliário que funciona como fundo histórico ao romance de Eça de Queiroz.

A novela histórica de Gonçalo Ramires, personagem central de A ilustre casa, neste sentido, é um relato implicado que revela em nível profundo a estagnaçâo dos valores hierárquicos que deram sustentaçấo ao que podemos identificar como modo de vida português até século XVIII. A decadência da Casa dos Ramires justifica um posicionamento crítico diante da fragilidade da sociedade tradicional lusitana que tem em Gonçalo um representante.

O tom medieval da novela de fidalgos em busca do resgate histórico da "casta dos Ramires" metaforiza na alusăo aos modelos medievais decadentes e denuncia, paradoxalmente, a decadência do conjunto de valores postos como tradicionais por Gonçalo Ramires. Do contraste entre a tradiçâo medieval e a nova sociedade emergente ao final do século XIX surge a metáfora da decadência econômica e moral atravessada por 
Gonçalo Ramires. Em A cidade e as serras teríamos um desdobramento deste percurso crítico, pois o contraste cidade versus campo sugere como tema de tese do romance que os modelos arcaicos sucumbem face à nova ordem social imposta a Portugal após o século XIX.

É no resgate irônico da tradiçâo centrada em um passado em muito decadente que Eça expóe por meio de seus dois romances a necessidade de superaçấo do passado como forma de apresentar novos rumos ao desenvolvimento de Portugal. É justamente por esta perspectiva que temos a possibilidade de leitura irônica como mola construtora do nacionalismo crítico de Eça de Queiroz. O resultado é a deflagraçăo da decadência econômica sentida pela impossibilidade de Gonçalo Ramires dar termo a sua novela, metáfora concreta da superaçăo dos modelos medievais que tem no fidalgo um exemplo.

Nos dois romances é latente a necessidade de inclusāo do homem português no processo de reorganizaçăo da naçăo. Retomando Viagens na minha terra, lembramos que para Garrett (1978) é preciso que o sujeito reconheça seu papel dentro do cenário tradicional e opte por valorizar sua cultura entăo na eminência da decadência; em Eça esta adesáo é o que determina a trajetória de perda das origens que movimenta a narrativa simbólica de A cidade e a serras e faz de Gonçalo Ramires um fidalgo sem pátria, sem espaço e, por isso, superado pela nova conjuntura política e econômica de Portugal ao final do século XIX.

Uma vez superada a dualidade inicial entre a permanência da tradiçấo e sua superaçăo os valores nacionais em Portugal conduzem a percepçăo em eco das advertências do velho do Restelho em Os Lusíadas. Gonçalo Ramires percebe a inoperância da tradiçâo histórica sem o diálogo com o novo, mas permanece preso ao passado. Essa nova forma de lidar com a realidade lusitana é metaforizada, dentro da Ilustre Casade Ramires, menos pelo esvaziamento do discurso histórico, antes pela deflagraçăo das transformaçôes sociais vividas pelos personagens centrais no romance.

Em Casa na Duna teríamos outro exemplo do desgaste dos valores do passado enquanto elemento utópico no nacionalismo português. Em Carlos Oliveira, já no início do século XX, a explicitaçáo do questionamento ao passado de conquistas do povo lusitano encontra na metáfora decadente da Casa na duna um exemplo da inoperância do passado ante as alteraçōes políticas e sociais em Portugal após o século XIX. A fábrica fracassada, o desmoronamento da "casa" construída metaforicamente no passado, areia, determina a trajetória de fracassos presentes no romance. Carlos Oliveira aponta para o fim de um percurso: a manutençâo do passado e a impossibilidade de regresso.

É por conta deste percurso decadente que a "estrada", metáfora da modernizaçâo do país, dá fim ao sonho da indústria de telhas e impossibilita a retomada da influência de Mariano Paulo, o que implica, na linha de leitura deste texto, na explicitaçấo do fim de uma época de glórias em que o sobrenome configura um sentido de plenitude e força política. Os personagens Gonçalo Ramires e Mariano Paulo náo conseguem revitalizar a tradiçăo que ironicamente tentam preservar, săo ícones de um passado que năo pode ser resgatado. O resultado é um lirismo melancólico preso ao passado lusitano e aos valores culturais do país ibérico, mas, ironicamente, superados pela modernizaçăo de Portugal no início do século XX. É neste contexto de ironia diante de uma tradiçấo decadente que procura perpetuar-se que se pode entender, conforme Saraiva (1990), o nacionalismo português como um movimento de resistência às constantes mudanças 
políticas e econômicas enfrentadas pela naçăo portuguesa ao longo do século XIX, o que revela, pela presença da ironia, a explicitaçấo de um dilema.

Esta tensâo diante do resgate das origens lusitanas pode ser encontrada, também, em autores lusitanos do século XX. Na poesia de Fernando Pessoa teríamos um dos exemplos mais emblemáticos. Os versos "Atravessa esta paisagem o meu sonho dum porto infinito/E a cor das flores é transparente de as velas grandes de grandes navios/ Que largam do cais arrastando nas águas por sombra /Os vultos ao sol daquelas árvores antigas" que abrem o poema "Chuva oblíqua"; bem como a obra enigmática de Alberto Caeiro em contraste ao tom cosmopolita de "Tabacaria", de Álvaro de Campos, fornece um exemplo da heterogeneidade do resgate cultural aqui comentado.

A ideia aqui defendida é a de que na valorizaçâo dos espaços culturais de representaçăo do homem lusitano a tensăo entre o pertencimento a naçăo e a presença de certo distanciamento do passado de plenitude conduz à fratura da imagem hegemônica associada ao nacionalismo como tema utópico na literatura portuguesa. Assis (1987), neste sentido, contempla uma ideia de fusâo de valores culturais que pressupôe o deslocamento do local enquanto espaço restrito de nacionalidade em direçáo a uma visăo mais ampla na qual local e universal encontram espaços de convivência tensiva no nacionalismo lusitano. Pensamos identificar, na linha de investigaçăo deste estudo, este percurso disperso, ainda que de forma simbólica, na tradiçâo literária portuguesa.

É por conta deste percurso dissonante - pertencer e ao mesmo tempo resignarse por este pertencimento à cultura portuguesa - que aludimos a um sentido irônico subterrâneo ao nacionalismo português. Em "Chuva oblíqua" o eu-lírico identificado ao espaço lusitano em transformaçăo é levado, pela necessidade de aceitaçăo do novo, ao contato com a transposiçấo do passado em um novo conjunto de valores culturais, agora mais híbrido.

\section{(...)}

O esplendor do altar-mor é o eu năo poder quase ver os montes

Através da chuva que é ouro tăo solene na toalha do altar...

Soa o canto do coro, latino e vento a sacudir a vidraça

E sente-se chiar a água no fato de haver coro...

A missa é um automóvel que passa;

Através dos fiéis que se ajoelham em hoje ser um dia triste...

Súbito vento sacode em esplendor maior

A festa da catedral e o ruído da chuva absorvendo tudo

Até só se ouvir a voz do padre água perder-se ao longe

Com o som de rodas de automóvel...

Apagam-se as luzes da igreja

Na chuva que cessa

$$
\text { (...) (PESSOA, 1989, p. 158) }
$$

O "esplendor do altar-mor" suplanta os "montes" e as referências ao interno, ligadas a descriçâo da igreja e seus rituais na missa, sâo apresentados em contraste com as referências ao moderno: automóveis e sons que advém do exterior. As referências lacônicas ao passado e ao som da chuva nos vitrais da igreja parecem reorganizar os 
sentidos do eu-lírico, face ao passado. A aparente dispersăo dos valores dogmáticos deslocados pelo olhar sinestésico do eu-lírico cria uma espécie de transe que, em nível profundo, silencia a missa via sensaçôes auditivas provocadas pela confluência sonora no poema. Este percurso desloca as imagens e rituais da missa, metáfora do passado, em direçáo ao novo, ironicamente, amalgamado ao fim da chuva no poema.

Ao questionar a validade da permanência aos valores tradicionais, missa, e indicar a presença do novo, "Chuva oblíqua" cria uma tangente para a percepçâo de um novo Portugal. O eu-lírico de "Chuva oblíqua", metáfora do novo, cai pelo "abismo feito de tempo" ao introduzir fleches cosmopolitas que funcionam como ironia diante do passado metaforizado na focalizaçâo ambígua dos elementos da tradiçâo em meio ao novo, novamente, fazendo referência a uma metáfora de modernizaçăo presente nos automóveis e nos sons que vem da rua a perturbar os que estăo dentro da igreja, ou seja, presos ao passado e assolado pela "chuva", o novo.

A evocaçăo do "carrossel" de lembranças da infância e do "jockey amarelo" seriam exemplos deste processo de atualizaçâo do passado de glorias pela "esfinge enigmática" que o poema "Chuva oblíqua" impóe como forma de observar a tradiçâo em uma perspectiva enviesada, oblíqua. Este posicionamento - questionar à tradiçăo por meio de novas referências ao tempo presente - possibilita perceber o incomodo do eu-lírico de "Chuva oblíqua" face à rigidez da tradiçăo no poema comentado.

Ao mesmo tempo poderíamos pensar na aproximaçăo ao tom irônico de Antônio Lobo Antunes em Os cus de Judas quando da ideia de pureza nacional, novamente pensando a fragilidade da busca lusitana por delimitar uma identidade presa aos valores lusitanos: pertencimento a terra e aos valores cristăos, lembrando Garrett (1978).

Fique comigo agora que a amanhă de Malanje incha dentro de mim, vibra dentro de mim, invertida, agitaçóes deformadas de reflexo, e estou sozinho no asfalto da cidade, perto dos cafés e do jardim, possuído de um insólito desejo sem objeto, indefinido e veemente, a pensar em Lisboa, na Gija ou no mar, a pensar nas casas de putas sob eucaliptos e nas suas camas repletas de bonecas e naperons. $O$ medo de voltar ao meu país comprime-me o esôfago, porque, entende, deixei de ter lugar fosse onde fosse, estive longe demais, tempo demais para tornar a pertencer aqui, a estes outonos de chuvas e de missas, estes demorados invernos despolidos como lâmpadas fundidas, estes rostos que reconheço mal sob as rugas desenhadas, que um caracterizador irônico inventou. Flutuo entre dois continentes que me repelem, nu de raízes, em busca de um espaço branco onde ancorar, e que pode ser, por exemplo, a cordilheira estendida do seu corpo, um recôncavo, uma cova qualquer do seu corpo, para deitar, sabe como é, a minha esperança envergonhada. (ANTUNES, 2003. p. 222)

Ao pensarmos em Os cus de Judas fica evidente năo só no excerto citado, mas ao longo do romance, que o nacional, no caso o lusitano, é contaminado pela visăo do personagem ambientado à África. A alusâo a uma impossibilidade do resgate do puramente lusitano aparece deslocada uma vez que o personagem "flutua" entre dois continentes. Com os pés firmes na duplicidade, no fragmentário o narrador reconhece sua hibridez. A "cordilheira estendida" comparada ao corpo da mulher, nâo só Gija, mas a mulher africana e negra simboliza o contato do português com o novo continente, fato que pode conduzir ao efeito metafórico associado à figura feminina no romance. 
Nele a mulher, Gija, surge como prolongamento do continente e, neste sentido, as "covas do corpo" alinhadas ao tom de cordilheira estendida, sempre às măos do narrador, compreende como o contato com o novo é traumático para o homem lusitano. Nesse contato, o narrador produz a reorganizaçăo dos valores do lusitano, agora incompreendido dentro de seu próprio conjunto de valores culturais e, ao mesmo tempo, deslocado pela condiçáo de estrangeiro da matriz cultural africana. A constataçâo da contaminaçâo do lusitano assume, assim, fator central na construçâo do romance de Lobo Antunes, fato prolongado pela ambiguidade do sentido de pertencimento aos dois espaços - Portugal e África - evocado no excerto; mas presente como eixo temático no romance de Antunes (2003).

O "aqui", nesse caso, evoca Portugal, mas também evidencia sua distância. Pensar nesta dinâmica - distanciamento e proximidade - conduz a valorizaçăo do contexto português nâo pela afirmaçăo do local, mas pela constataçăo de sua hibridez no paralelo com o outro, o estrangeiro. É neste contexto de questionamento ao local que podemos situar a obra de Lobo Antunes e, mais especificamente, a narrativa irônica de Os cus de Judas, como exemplo de um percurso questionador face ao nacionalismo utópico enquanto tema na literatura portuguesa.

No olhar irônico, anunciado em nível profundo em Os lusíadas e materializado ao longo do tempo encontramos o sentido de hibridez cultural do lusitano, o que proporciona a reflexăo sobre o processo colonial português como uma das formas de externar a tensăo nacionalista em Portugal.

\section{CONSIDERAÇÕES FINAIS}

A concluirmos este texto achamos prudente comentar que nosso objetivo foi estabelecer uma linha de discussăo que tomou o tema nacionalista como uma constante dentro da tradiçấo literária portuguesa. Apontamos para a possibilidade de pensar tensôes na representaçăo do nacionalismo português.

Sabemos da brevidade do estudo, porém, acreditamos que no diálogo entre tradiçăo e inovaçăo temática na literatura portuguesa pensamos uma forma irônica na constituiçấo do homem português como representante unilateral de sua cultura. Em outros termos, ao pensar um viés irônico no nacionalismo lusitano; compreendemos que existe uma ambiguidade na representaçâo unilateral dos valores culturais lusitanos após o contato com novas formaçôes culturais ao longo da História.

Lembramos à guisa de conclusăo, que o nacionalismo na tradiçấo portuguesa é uma importante fonte temática, mas, em seu interior, compreendemos um traço irônico. 


\section{REFERÊNCIAS}

ANTUNES, A. L. Os cus do Judas. Rio de Janeiro: Objetiva, 2003.

ASSIS, M. de. "Instinto de nacionalidade". In. . Obras completas: crítica. Săo Paulo: Aguillar, 1987. pp. 767-778.

BAKHTIN, M. A estética da criaçáo verbal. Săo Paulo: Cultrix, 1994.

BERRINI, B. Brasil e Portugal: a Geraçăo de 70. Porto: Campo das Letras, 2003. BRANCO, Camilo C. Cancioneiro alegre de poetas portugueses e brasileiros (comentado por Camillo Castello Branco). Lisboa: Mem. Martins: Europa-América, 1984.

BLOOM, H. A.; Angústia da influência. Sāo Paulo: Cultrix, 1994.

CASTRO, F. de. Ao fim da memória (1906-1939). Lisboa: Círculo de Leitores, 1986.

CAVALCANTI, P. Eça de Queiroz, agitador no Brasil. 2. ed. Săo Paulo: Companhia Editora Nacional, 1966.

CERVO, A. L.; MAGALHĂES, J. C. de. Depois das Caravelas: as relaçôes entre Portugal e o Brasil (1808-2000). Organizaçaáo e apresentaçăo de Dário Moreira de Castro Alves. Lisboa: Instituto Camōes, 2000.

CIDADE, H. Luís de Camóes: a obra e o homem. 4. ed. Lisboa: Arcádia, 1980

FIGUEIREDO, Fidelino de. História Literária de Portugal. Săo Paulo. Companhia Editora Nacional, 1996.

GARRETT, A. A restauraçáo das letras, em Portugal e no Brasil em meados do século XVIII. In. CESAR, G. (Org.). Historiadores e críticos do romantismo: 1 a contribuiçâo européia: crítica e história literária. Sáo Paulo: Edusp, 1978.

OLIVEIRA, C. A casa na duna. Sáo Paulo: Duas cidades, 1990.

PEIXOTO, M. D. F. A Revista Brasil-Portugal (1907-1910): elementos para uma leitura das relaçôes culturais luso-brasileiras. Coimbra, 2000. 103p. Trabalho de Conclusâo de Curso em História. Universidade de Coimbra.

PESSOA, F. Obras completas de Fernando Pessoa: poesia. Săo Paulo: Ática, 1989.

QUEIROZ, E. A ilustre casa dos Ramires. Săo Paulo: Objetiva, 2000.

QUEIROZ, E. Acidade e as serras. Săo Paulo: Objetiva, 2000.

RAMOS, V. Introduçāo aos Lusíadas. In. CAMŌES, L. V. Os Lusíadas. Săo Paulo: Cultirx, 1974, pp. 7-25.

ROSENFELD, A.; Aspectos do romance moderno. In. . Texto/Contexto I. Sáo Paulo: Perspectiva, 1976.

SARAIVA, A. J; LOPES.; O. História da Literatura Portuguesa. Porto. Porto Editora, 1990. SARAMAGO, J. A jangada de pedra. Sáo Paulo: Companhia das Letras, 2006.

TODOROV, T. Os gêneros do discurso. Săo Paulo: Record, 1993. 